O eixo e a roda, Belo Horizonte, v.25, n.2, p. 177-199, 2016

\title{
O prisma dos grupos: a difusão nacional do modernismo e a poesia de Augusto Meyer
}

\section{The prism of the groups: the national diffusion of the Brazilian modernism and the poetry of Augusto Meyer}

Leandro Pasini

Universidade Federal de São Paulo (UNIFESP), São Paulo / Brasil leandro.pasini@unifesp.br

Resumo: O objetivo deste ensaio é estudar a lógica e o funcionamento da ideia de grupo no modernismo brasileiro, sua relação com o conceito de arquivo, bem como a interação entre o trabalho coletivo e a originalidade individual a partir da poesia de Augusto Meyer.

Palavras-chave: modernismo brasileiro; grupo; arquivo; poesia modernista; Augusto Meyer.

Abstract: The purpose of this article is to study the logic and the workings of the idea of group in Brazilian modernism, its relationship with the concept of archive, as well as the interaction between collective work and individual originality from the perspective of Augusto Meyer's poetry.

Keywords: Brazilian modernism; group; archive; modernist poetry; Augusto Meyer.

Recebido em 21 de março de 2016.

Aprovado em 22 de agosto de 2016. 
[os ismos d]e nenhum modo entravaram as forças produtivas individuais, mas antes as intensificaram, e graças sobretudo a um trabalho coletivo.

ADORNO, T. W. Teoria estética.

Mário de Andrade (1924, p. 32), ${ }^{1}$ ao resenhar Memórias sentimentais de João Miramar, de Oswald de Andrade, faz um balanço do movimento modernista em 1924 e argumenta que se trata de um "grupo, não escola, grupo que por vário caminho se dirige para o mesmo fim". Por que "grupo", e não "escola"? Certamente porque a ideia de escola remeteria a algum tipo de unidade estilística, em que a personalidade e a originalidade do autor ficariam submetidas a um princípio estético superior a elas. A noção de grupo, contudo, tem caráter dinâmico, pois o seu eixo é a relação entre um consenso quanto à finalidade (no caso do texto de Mário, a pesquisa estética sobre a realidade brasileira) e a diversidade de meios e caminhos pelos quais se busca atingir determinado fim. Um grupo, desse modo, constitui um conjunto de singularidades que funciona com originalidade e dinâmica própria. Nesse sentido, o objetivo deste ensaio é estudar a lógica e o funcionamento da ideia de grupo no modernismo brasileiro, bem como a interação entre o trabalho coletivo e a originalidade individual a partir da poesia de Augusto Meyer. Essa perspectiva elabora a ideia de grupo tanto como um elemento externo à obra literária, em que autores e agentes sociais (críticos, editores, jornalistas, publicistas, amigos, familiares, políticos, pessoas vinculadas a instituições e leitores) marcam uma posição em um campo literário (BOURDIEU, 1994), quanto como um fator produtivo na composição de obras artísticas, tendo em vista as influências recíprocas, as leituras prévias, a relação entre recepção crítica e criação, entre outras formas de interação estética e intelectual.

Nos antecedentes da Semana de Arte Moderna, ainda segundo Mário de Andrade (2002, p. 254, grifo meu), "a convicção de uma arte nova, de um espírito novo, desde pelo menos seis anos viera se definindo no... sentimento de um grupinho de intelectuais paulistas". Novamente, a ideia de um grupo, ainda que pequeno, surge como motor do modernismo no Brasil. A sua função no impulso inicial do movimento foi decisiva, o que pode ser demonstrado pela comparação da atuação inicial de

\footnotetext{
${ }^{1}$ Republicado em BATISTA; LOPEZ; LIMA, 1972, p. 219-225.
} 
Mário com os percalços dos primeiros impulsos de Oswald de Andrade. Mário, como se sabe, teve o seu poema "Tu" publicado por Oswald em sua coluna no Jornal do Commercio, em que o apresenta como "O meu poeta futurista". A experiência de Oswald é qualitativamente diferente. Em 1912, em Paris, toma contato, ainda que vago, com o futurismo e o verso livre e, ao retornar a São Paulo, compõe um poema "sem rima nem metro, intitulado 'Último passeio de um tuberculoso, pela cidade, de bonde"” (BRITO, 1969, p. 4). Os amigos, porém, "zombaram da poesia, considerando estapafúrdios os versos, que destrilhavam dos cânones e regras admitidos e consagrados" (BRITO, 1969, p. 4). Esse fato inibiu momentaneamente o ímpeto experimental do poeta, que se desfez do poema, do qual não se tem registro.

A contraposição dessas duas experiências nos fornece a chave inicial para entender a importância dos grupos na consolidação de um movimento literário: no primeiro caso, de Mário de Andrade, vemos o que André Breton (1992, p. 705) chama de "acaso favorável" (hasard favorable), enquanto no caso de Oswald estamos diante do "acaso desfavorável" (hasard défavorable). Segundo Breton (1992), o acaso favorável faz com que soluções individuais acolhidas por um grupo se transformem em uma "segunda finalidade" (finalité seconde), em que as vontades se conjugam para um objetivo comum. Ao contrário, o acaso desfavorável faz com que soluções individuais sejam desconsideradas e se percam no plano do acidental.

Assim, o grupo, ao funcionar como um "acaso favorável", confere, por um lado, validade coletiva a um ato individual e, por outro, contribui coletivamente para os atos de um indivíduo. Notese, de passagem, como o acaso favorável de uma ideia de renovação artística uniu um grupo heterogêneo para promover a Semana de Arte Moderna, que reuniu figuras de prestígio econômico e social (Paulo Prado, René Thiollier), de prestígio literário e acadêmico (Graça Aranha), escritores que também eram jornalistas (Menotti del Picchia, Oswald de Andrade), artistas plásticos (Anita Malfatti, Brecheret), um músico como Villa-Lobos e uma gama de poetas, desde os já conhecidos Ronald de Carvalho e Guilherme de Almeida, aos menos conhecidos, e por vezes inéditos, Mário de Andrade, Luís Aranha, Tácito de Almeida, Sérgio Milliet e Agenor Barbosa. A conclusão a que se chega, em face de um grupo heterogêneo como esse, é a de que, por um lado, há pontos de convergência e divergência que se mantêm em constante tensão e, 
por outro, trata-se de um movimento que assume um caráter público e coletivo, que busca declarada e programaticamente ocupar e sulcar o campo artístico e intelectual brasileiro a partir de uma ideia vaga - e por isso mesmo compartilhada - de uma arte "nova" e um pensamento "novo".

\section{Desenvolvimento do modernismo em São Paulo}

Após a Semana, esse impulso de renovação artística e intelectual foi continuado pela revista Klaxon (1922-1923), em torno da qual se reuniu a primeira composição do grupo paulista. Além da esfera pública da revista e dos jornais em que o movimento polemizava e expunha ideias, publicava suas criações e resenhava obras, iniciou-se uma correspondência entre muitos de seus integrantes, criando assim uma ampla teia epistolográfica nacional e internacional ainda não inteiramente mapeada. O processo de composição, decomposição e recomposição de grupos pode ser observado de modo exemplar (embora não normativo) em São Paulo. A primeira dissidência de Klaxon, com Menotti del Picchia à frente, aglutinou-se em torno da revista Novíssima (1923-1925), em que surgem os nomes de Cassiano Ricardo e Plínio Salgado, que criarão posteriormente o grupo Verde-Amarelo, em seguida a Anta, a Bandeira e o Integralismo (GUELFI, 1987). O grupo inicial de Klaxon se recompôs em Terra Roxa... e outras terras (1926), acrescido da plataforma da poesia pau-brasil e de uma ênfase na história de São Paulo. Depois disso, a primeira dentição da Revista de Antropofagia (1928) criava um novo veículo para o mesmo grupo que, no entanto, a partir da segunda dentição, em 1929, seria cindido pela ruptura entre Oswald e Mário. Essa ruptura marca a década de 1930. Por um lado, Mário aglutina em torno de si uma linha de continuidade do movimento com a Revista Nova (1931-1932), junto de Alcântara Machado e Paulo Prado; com a SPAM (Sociedade Pró-Arte Moderna), ao lado de Lasar Segall (1932-1934); e, por fim, à frente do Departamento de Cultura (1935-1937), onde estreita os seus laços com Paulo Duarte. Por outro, Oswald e Tarsila se juntam a Flávio de Carvalho, a figura mais dinâmica da década de 1930 no modernismo paulista, que funda o CAM (Clube de Artistas Modernos, 1932-1934), o Teatro de Experiência (1933) e é um dos articuladores do Salão de Maio (1937-1939), publicando o número único da Revista Anual do Salão de Maio (RASM, 1939) (LEITE, 2008, p. 113-132). 
Da Semana de 22 até a Revista Anual do Salão de Maio, podemos acompanhar praticamente duas décadas de desenvolvimento contínuo dos grupos modernistas de São Paulo. O desdobramento do movimento modernista na década de 1940 no contexto paulista ocorreu a partir de um encontro em 1935. Aí os jovens Paulo Emílio Salles Gomes e Décio de Almeida Prado se uniram ao grupo de Oswald, Tarsila e Flávio de Carvalho no ideado e não consolidado "Clube do Quarteirão" (FONSECA, 2008, p. 247). Paulo Emílio e Décio lançaram então o número único da revista Movimento (1935), que contava ainda com contribuições de Sérgio Milliet e Mário de Andrade. Como relembra Décio: "por essa ocasião, entramos em contato com os escritores modernistas de São Paulo" (CAVALCANTE, 1978, p. 213). O contato desse momento reaparece na constituição do grupo da revista Clima (1941-1944), que contava com Antonio Candido, Lourival Gomes Machado e Gilda Rocha, além dos já citados Décio e Paulo Emílio (CANDIDO, 2007, p. 144-145). Tratava-se da primeira geração da recém-fundada Universidade de São Paulo (1934), cuja admiração pelo modernismo se vinculava à atitude mental renovadora do movimento, a seu projeto de pesquisa da realidade brasileira e a sua dimensão intelectual construtiva, que erigia em modelo sobretudo o trabalho intelectual de Mário de Andrade (CANDIDO, 2007, p. 147). O modernismo, então, se insere em uma órbita institucional que vai decidir sobre o seu estatuto no modo de conceber a própria ideia de literatura brasileira. A partir desse momento, e sobretudo pelo trabalho de pesquisa, docência, orientação, participação institucional e formulação teórica de Antonio Candido, o modernismo ganha o espaço da Universidade.

Esse processo institucional se completa de modo prático com a aquisição pela Universidade de São Paulo, em 1968, da biblioteca pessoal de Mário de Andrade e de todo o seu arquivo de fichas, obras de arte, correspondência, manuscritos de outros autores, entre outros documentos (PAULA, 2007, p. 4). Ao adquirir essa presença patrimonial, cujo desenvolvimento universitário cobre um arco que vai das pesquisas iniciais sobre a marginalia e as fontes da obra do escritor ao índice recente de sua correspondência, a obra de Mário e sua metonímia - o movimento modernista - passam a operar segundo outra dinâmica, em que os trajetos de uma pesquisa dentro de um acervo constituído ou em 
processo de constituição definem quais narrativas são válidas ${ }^{2}$ no interior de uma construção discursiva, o modernismo, cujo valor se apresentaria a priori como algo fixo.

\section{Do grupo ao arquivo}

$\mathrm{Na}$ introdução de seu livro Um homem sem profissão (1954), Oswald de Andrade (2002, p. 36) relata: "Antonio Candido diz que uma literatura só adquire maioridade com memórias, cartas e documentos pessoais e me fez jurar que tentarei escrever já este diário confessional". Desse modo, a idade adulta de uma literatura supõe a existência de um arquivo composto não apenas das obras de seus autores, mas também de um acervo documental que, ao mesmo tempo, ratifica o valor do autor presente no arquivo e abre diversos caminhos para a avaliação de sua obra e de seu espólio, bem como de suas relações literárias e sociais, sua biblioteca e marginalia, fotos, versões textuais, correspondência etc.

Uma "topologia privilegiada", na expressão de Derrida (2001, p. 13), o espaço do arquivo "marca essa passagem institucional do privado ao público" (DERRIDA, 2001, p. 13) e, assim, mais do que uma obra literária, temos diante de nós um conjunto de materiais heterogêneos, "uma quase infinidade de camadas, de estratos arquivais por sua vez superpostos, superimpressos e envelopados uns nos outros" (DERRIDA, 2001, p. 35). Qual é a relação entre grupo e arquivo? A força de um grupo consiste, entre outras coisas, na possibilidade de dar caráter coletivo a uma obra individual e inseri-la em uma narrativa coerente que marca a presença desse grupo em um campo intelectual.

\footnotetext{
${ }^{2}$ Outras narrativas sobre a institucionalização do modernismo incluem a participação dos intelectuais no Estado Novo, a interpretação do movimento feita pelo concretismo e pelo tropicalismo, assim como a criação do Arquivo-Museu da Fundação Casa de Rui Barbosa (fundado em 1972). Com exceção desta última, nenhum dos movimentos possui sede institucional. A proximidade com o poder no Estado Novo foi um polo de gravitação do modernismo por meio de Drummond, Augusto Meyer, Rodrigo M. F. Andrade, entre outros, mas não é por meio dessa proximidade que ocorre a passagem do grupo ao arquivo, como será desenvolvido a seguir. Pense-se, por exemplo, no esquecimento em que caiu uma das figuras mais "legitimadas" então, Cassiano Ricardo. Além disso, somente algumas décadas depois do fim da ditadura estadonovista, em 1972, Drummond propôs a criação de um Arquivo-Museu da literatura brasileira (XAVIER, 2008, p. 26-27).
} 
Um grupo pode ser considerado bem-sucedido se é capaz de formar um ponto de vista particular, uma perspectiva pela qual, ao narrar a própria história, ele constitui um modo diferente de narrar a história da literatura (e potencialmente da cultura). ${ }^{3}$ Nesse sentido, o grupo é um ponto de partida, não de chegada. A criação do arquivo inicia a sobrevida de um grupo, que passa, a partir de então, a receber uma progressiva legitimação institucional e um processo contínuo de reavaliações.

Desde a publicação de Intelectuais e classe dirigente no Brasil (1920-1945), de Sérgio Miceli, em 1979, a pesquisa da relação entre o intelectual modernista e o poder ampliou o potencial explicativo e especulativo do modernismo brasileiro. Segundo essa perspectiva, o modernismo e o getulismo caminham juntos e, no final, se fundem na constituição de um país nacionalista, centralizado, burocrático, patrimonial e autoritário. A despeito do caráter taxativo e antiliterário de suas conclusões, é importante notar que esse ponto de vista trouxe para o primeiro plano dos estudos literários uma gama de novos elementos - documentação biográfica, verificação das carteiras de trabalho, inventários de bens de família, editoras e seus catálogos, a influência social e política dos parentescos e dos afetos, a lógica interna das instituições brasileiras e, no limite, a própria dinâmica das instituições universitárias em que esses estudos transitam. Tais elementos ganham dimensão interpretativa e buscam reconfigurar a ideia que fazemos da literatura e de suas esferas legitimadoras.

A ideia de grupo ganha força nesse quadro justamente por se constituir pela intersecção de elementos externos e internos à obra literária, isto é, tanto pelos mecanismos de autolegitimação e institucionalização quanto pela composição e recepção de obras literárias. Nesse sentido, tomando como base a produção poética relacionada aos grupos, é possível acompanhar ao longo da década de 1920 o modo como o modernismo se torna um movimento literário de proporções nacionais, na medida em que surgem diversos grupos em diferentes cidades do país. No Rio de Janeiro, Graça Aranha, Ronald de Carvalho e Renato de Almeida, animados pelo "objetivismo dinâmico" exposto por Graça Aranha em A estética da vida (1921), se agrupam em torno das revistas Movimento (1928) e Movimento Brasileiro (1928-1930). Inicialmente próxima a eles está a dupla Sérgio Buarque de Holanda e Prudente de Moraes, neto,

\footnotetext{
${ }^{3} \mathrm{O}$ mesmo tema, com uma perspectiva diferente, está em Moreschi (2010).
} 
que dirige a revista Estética (1924-1925) e participa, junto de Rodrigo M. F. de Andrade, da segunda fase da Revista do Brasil (1926-1927). Tanto Sérgio quanto Prudente se afastam progressivamente do grupo de Graça para iniciar um diálogo mais cerrado com o grupo paulista de Klaxon, ao qual também se vincula Manuel Bandeira por sua amizade com Mário. Com feição própria, Ismael Nery gerou um grupo em torno de si e de seu "essencialismo", cujo principal expoente poético, além dele mesmo, foi Murilo Mendes. Paranaenses de origem e herdeiros do simbolismo paranaense, Tasso da Silveira e Andrade Muricy fundaram no Rio a revista de tendência modernista espiritualista Festa (1a fase: 1927-1928; 2a fase: 1934-1935), que contava ainda com Murilo Araújo e Cecília Meireles.

Em Belo Horizonte, congregaram-se em torno de A Revista (1925-1926) Carlos Drummond de Andrade, João Alphonsus, Pedro Nava, Emílio Moura e Martins de Almeida. Pouco tempo depois, em 1929, Achilles Vivacqua e João Dornas Filho publicam na capital mineira a revista leite criôlo com uma leitura singular da antropofagia oswaldiana. Aderiram também ao modernismo as cidades mineiras do interior, sobretudo Cataguases, com Verde (1927-1928), de que se destacam Rosário Fusco, Ascânio Lopes e Guilhermino César, mas também Itanhandu, com a revista Electrica, de Heitor Alves.

Em Porto Alegre, convivendo com o simbolismo de Eduardo Guimarães e Mansueto Bernardi, constitui-se o grupo modernista gaúcho, com a revista Madrugada (1926), a Página Literária (19271931) do Diário de Notícias e a Revista do Globo (1929-1931), de que fazem parte Augusto Meyer, Athos Damasceno Ferreira, Theodemiro de Tostes e Vargas Neto. No contexto gaúcho, a noção de regionalismo participa ativamente da estética modernista, conferindo originalidade ao grupo, junto da forte influência simbolista. Já em Pernambuco, o ardor modernizante de Joaquim Inojosa - que publica Mauriceia (1923-1924) - se choca com o ideal regionalista de Gilberto Freyre. Além disso, oscilações entre o moderno e o regional vão marcar os dois poetas da Revista do Norte (1923-1926): Benedito Monteiro e Joaquim Cardozo. Essa oscilação encontra uma síntese na poesia de Ascenso Ferreira, em que o dinamismo e os procedimentos da estética modernista recuperam ritos e expressões tradicionais e populares do Nordeste. O mesmo processo de transfigurar os elementos locais da cultura e da natureza está presente em Natal, onde Luis da Câmara Cascudo e principalmente Jorge 
Fernandes, com seu Livro de poemas (1927), configuram uma proposta modernista original.

Em Belém, o modernismo literário é impulsionado por Bruno de Meneses e se agrupa em torno da revista Belém Nova (1923-1929), em que participam De Campos Ribeiro, Eneida e Abguar Bastos. Os ritos afro-brasileiros que Bruno de Meneses funde aos ritmos modernos de Batuque (1931) são complementados pelo manifesto Flami-n'-assú (1927), de Abguar Bastos.

A busca de uma fusão entre a herança cultural do passado escravista e os ritmos novos está presente nos Poemas (1927) de Jorge de Lima, publicados em Maceió, onde ocorre, em 1928, a Festa da Arte Nova, em que participam, entre outros, Jorge de Lima, Carlos Paurílio e Valdemar Cavalcanti. No mesmo ano, e acrescido de Alóísio Branco, o grupo publica a revista Maracanan, que será seguida por Novidade (1931), na qual publica Graciliano Ramos e é também possível ler versos do futuro crítico Álvaro Lins e do artista plástico Santa Rosa.

Mais próximo das ideias de Graça Aranha e do espiritualismo de Festa esteve o eixo modernista de Salvador. Na abertura da primeira revista do movimento, Arco \& Flexa (1928-1929), Carlos Chiacchio publica o seu manifesto "Tradicionalismo dinâmico", com o qual dialogam direta ou indiretamente os demais poetas da revista, como Eugênio Gomes e Carvalho Filho. Paralelo a esse grupo surgiu a revista Samba (1928-1929), em que publicam poetas como Alves Ribeiro e Elpídio Bastos. Sob o signo de Ronald de Carvalho, em Fortaleza, Jáder de Carvalho, Sidney Netto, Mozart Firmeza (Pereira Jr.) e Franklin Nascimento publicam o livro coletivo O canto novo da raça (1927). Em seguida, o grupo cearense intensifica o seu nacionalismo literário combativo, sobretudo pela contraposição entre norte e sul do Brasil, nas revistas Maracajá (1929) e Cipó de fogo (1931). Aí escrevem e polemizam Rachel de Queiroz, Mário de Andrade (homônimo do poeta paulista) e Edgar Alencar.

Perceber as conexões entre grupos modernistas pelo país, ainda que de modo resumido, esquemático e privilegiando a expressão poética, contribui para se ter a dimensão nacional do movimento. Assim, embora a construção paradigmática da história do movimento se baseie no grupo paulista, sobretudo naquele que vai de Klaxon a Clima e de Clima ao Arquivo, vê-se, de fato, que a sua dinâmica se desdobra em uma multiplicidade de pequenos grupos, revistas, núcleos originais de 
produção literária, intelectual e de polêmicas intra e extramodernistas. Cada grupo é, ao mesmo tempo, um fenômeno singular e interconectado com outros grupos. Caso fosse exclusivamente paulista, o modernismo seria um movimento regional, até mesmo provinciano, e entraria para o capítulo dos exotismos locais. Contudo, quando se trata do modernismo difundido pelo território brasileiro, percebe-se a constituição incompleta, insuficiente do arquivo. Ainda não se incorporou na historiografia e na crítica do movimento o cruzamento das suas diversas manifestações, não se elaborou uma narrativa que dê conta dessa complexidade, que não pode ser entendida somente como uma extensão dos programas literários de Mário, Oswald ou Graça Aranha. Conferir no plano da crítica a autonomia que esses grupos reivindicaram em seu momento histórico pode gerar uma reciprocidade das perspectivas, sem a delimitação de um centro e suas periferias em plano nacional, mas formando um prisma em que os pontos de vista criados a partir de cada experiência local configuram seu próprio método para ler as demais manifestações do movimento. A recomposição, então, da dialética entre o esforço coletivo e público dos grupos e a originalidade individual dos autores e obras é fundamental para o desenvolvimento desta proposta.

Diante disso, pode-se concluir que a difusão nacional do modernismo teve dois efeitos e uma consequência. Em primeiro lugar, desprovincianizou o movimento, fazendo com que as suas propostas fossem verificadas ao longo de boa parte do país e acrescidas de outras plataformas, impedindo, assim, que o movimento se reduzisse a uma singularidade paulista e carioca. Em segundo lugar, a extensão nacional do modernismo permite mapear o modo pelo qual os círculos letrados urbanos de todo o país puderam se posicionar em relação às transformações estéticas, sociais, urbanas e tecnológicas (e suas implicações ideológicas reais ou imaginadas), bem como veicular uma imagem renovada de si e de suas relações com o poder e os setores populares, auxiliados nesse aspecto pelo nacionalismo literário póspoesia pau-brasil. Como consequência, a noção de sistema literário se amplifica, criando uma teia de escritores e leitores em âmbito nacional que debatiam propostas estéticas relativamente comuns. Ocorre assim uma espécie de "federalização" da literatura brasileira na década de 1920.

O estudo da lógica dos grupos, com a sua dimensão simultaneamente coletiva e individual, pode servir de entrada para uma nova compreensão do modernismo no Brasil. O principal elemento coesivo de um grupo é a 
criação de uma revista, de um órgão em que seja visível um conjunto de procedimentos e atitudes que incluam o manifesto e o editorial, a criação e a crítica, além de entrevistas e polêmicas, bem como a porosidade ao espaço extraliterário, que comparece na publicidade presente na revista, na distribuição, no financiamento, na disposição da página, escolha do papel e tipografia, entre outros elementos. Além de constituir a imagem de um grupo e de sua relação com o restante do campo cultural, uma revista pode abrir-se a uma interação com os demais grupos, com os quais é possível juntar forças ou criar antagonismos. ${ }^{4}$

Contudo, esse espaço aberto e dinâmico da revista convive com a presença de um líder ou, ao menos, de uma figura que se impõe como modelo, exemplo ou referência, como foram Graça Aranha, Mário de Andrade, Oswald de Andrade, Carlos Drummond de Andrade e Augusto Meyer. ${ }^{5}$ Nesse sentido, verifica-se em todo grupo uma tensão entre a circulação de ideias de seus participantes e o poder de julgar, excluir, incluir, definir e lançar programas, exercido por uma figura mais ou menos dominadora. Pode-se assim pensar na ideia de grupo como um conjunto de singularidades, em que os seus participantes interagem por meio de sinergia e conflito. A isso corresponde o caráter efêmero e transitório dos grupos modernistas, em que formações se congregam e desagregam de modo por vezes vertiginoso. Muito disso pode ser atribuído ao significado do grupo para o artista individual: se, por um lado, a filiação a uma

\footnotetext{
${ }^{4}$ Em estudo sobre a revista estadunidense Others, Churchill (2006, p. 5, tradução minha) afirma que "pequenas revistas demonstram o quanto havia de intercâmbio entre diversos círculos artísticos" ("Little magazines demonstrate how much boundary crossing occurred between various artistic circles"). A mesma ideia reaparece em estudo sobre o modernismo chinês: "valores compartilhados cortavam transversalmente a composição dos grupos literários" ("shared literary values cut across the membership lines of literary groups”) (DENTON; HOCKX, 2008, p. 14, tradução minha).

5 "Sem dúvida, o líder de um grupo era o catalizador mais importante na criação do grupo e no processo de conferir-lhe personalidade. [...] [os líderes] compartilham qualidades estimulantes: energia, visão, dinamismo, dedicação; [...] devotados a promover o talento novo, eles, por sua vez, eram um polo de atração natural desse talento" ("Without question, the group's leader was the single most important catalyst in creating the group and making it a force to be reckoned with. [...] [the leaders] shared galvanizing qualities: energy, vision, dynamism, dedication; [...] devoted to promoting new talent, they, in turn, were natural magnets for that talent") (COHEN, 2008, p. 6, tradução minha).
} 
proposta coletiva confere visibilidade e prestígio, por outro, ela pode ser sentida como uma restrição, um limite, uma fronteira que a demanda de originalidade frequentemente transborda.

A constituição do arquivo, nesse sentido, permite tanto recompor o grupo em seu estado de fugacidade e permanente tensão, quanto abrir o grupo a uma nova dinâmica a partir da sua vinculação à história e à crítica literária.

\section{Futurismo, simbolismo, pau-brasil e regionalismo}

As relações e as interconexões entre os grupos dentro do modernismo compõem um mapa dentro do qual é possível reconfigurar o todo de modo diferente, considerando cada um dos pontos. A especificação do ponto de vista determina o trajeto a ser percorrido. Assim, para abordarmos o modernismo a partir do grupo gaúcho de Madrugada e da poesia de Augusto Meyer, precisamos recompor alguns dos caminhos do modernismo pelo Brasil.

Embora a primeira manifestação pública e coletiva autoconsciente do movimento tenha sido a Semana de Arte Moderna, ela não foi o único - talvez nem o principal - fator decisivo para a nacionalização do modernismo. Outros fatores, tanto extra quanto intraliterários tiveram peso na constituição dos diálogos e polêmicas literárias entre os grupos. $\mathrm{O}$ evento mais escandaloso levado a cabo pelo modernismo foi a ruptura de Graça Aranha com a Academia Brasileira de Letras em 1924, por ocasião da rejeição de seu projeto de modernização dessa instituição, que Graça apresentou junto com o seu discurso "O espírito moderno". Enquanto a Semana teve pouca repercussão nos jornais do país, a ruptura do escritor chegou a ser noticiada por telegrama até no jornal Correio da Pedra, de Vila de Pedra, no sertão de Alagoas (SANT'ANNA, 1980, p. 107). Se o efeito de choque foi causado por Graça, a divulgação mais propriamente discursiva do movimento modernista foi levada a cabo por Guilherme de Almeida, que, em 1925, viaja para Porto Alegre, Recife e Fortaleza a fim de pronunciar a conferência "Revelação do Brasil pela poesia moderna". Além disso, não se pode subestimar a influência da correspondência de Mário de Andrade, que ao longo da década de 1920 trocou cartas com Bandeira, Drummond, Câmara Cascudo, Ascenso Ferreira, Augusto Meyer, entre muitos outros. 
Dentre os fatores intraliterários, tomando como base especificamente a poesia, foi a ruptura programática das convenções do verso, sobretudo da métrica, que impulsionou o movimento. Embora o uso do verso livre já ocorresse no Brasil desde 1900, com Guerra-Duval (RAMOS, [s.d.], p. 26), e fosse praticado por Manuel Bandeira em Carnaval (1919), foi com Pauliceia desvairada (1922), principalmente com o "Prefácio interessantíssimo", que a experimentação com o verso assumiu uma atitude combativa contra o parnasianismo e uma demanda de ocupar o espaço cultural em que ele mantinha a hegemonia. Complementando o "Prefácio" com o livro A escrava que não é Isaura (1925), Mário propunha uma poética da modernidade em que o dinamismo da realidade e o do sujeito lírico estivessem intimamente relacionados. Essa correlação entre a modernidade poética e a modernidade social, cultural e urbana delimitava as fronteiras regionais do modernismo brasileiro, fazendo com que ele correspondesse somente às cidades em processo de industrialização, São Paulo à frente. ${ }^{6}$ Entretanto, na medida em que os diálogos modernistas de Mário, Tarsila e Oswald procuravam uma solução para a relação entre a vanguarda parisiense e a experiência local brasileira (DANTAS, 1996), o surgimento de um nacionalismo literário em que se entrelaçavam pesquisa nacional e experimentação literária ofereceu uma síntese à questão. Nesse momento, tanto o Manifesto da poesia pau-brasil (1924), de Oswald, quanto o poema "Noturno de Belo Horizonte" (1924), de Mário de Andrade, veicularam a fórmula que permitiu que o modernismo se tornasse um programa nacional: a sociabilidade agrária, sobretudo a da infância, a coexistência da cultura europeia com as tradições indígenas e africanas, as incongruências ideológicas e cotidianas de uma sociedade em que as pretensões cosmopolitas de sua elite conviviam com a realidade semicolonial do país tornaram-se material para uma forma literária

\footnotetext{
${ }^{6}$ Jorge de Lima, por exemplo, assim se expressa quanto ao contexto alagoano: “Ouvi um futurista: 'Interpretemos a harmonia das grandes fábricas, as vozes das metrópoles, dos cais rumorosos, os sonhos dos arranha-céus'. Como poderia, meus amigos, como poderia Ranulfo Goulart, este doce lírico da rua da Igreja interpretar todas estas coisas assombrosamente grandes e pavorosamente ágeis se o nosso mavioso parnasiano jamais viu sobrados mais altos que aqueles da rua do Comércio?" (LIMA, 1927 apud SANT'ANNA, 1980, p. 61).
} 
inovadora e provocativa. ${ }^{7}$ A partir de então, o modernismo brasileiro passa a prescindir da modernidade técnica e pode explorar como atualidade estética o nosso cotidiano social e psicológico, fazendo, assim, com que todos os nossos letrados se transformassem em modernistas em potencial.

Como se trata de uma fórmula que inclui, por um lado, a experimentação formal e, por outro, o nacionalismo literário, o modernismo brasileiro, a partir de 1924, adquire afinidades com dois momentos das produções literárias locais: o regionalismo como atitude afim do nacionalismo e os grupos simbolistas como antecessores ou contemporâneos dos experimentos poéticos. É preciso ter em mente, entretanto, que a atualidade do regionalismo e do simbolismo a partir de 1922 deve-se às formulações programáticas, públicas e coletivas dos grupos modernistas que, nesse sentido, atualizaram as produções artísticas locais. Não se trata, por isso, de "precursores" ou de "modernistas antes de 1922", mas de vasos comunicantes do espaço literário brasileiro que renovam a sua presença artística e intelectual a partir do desenvolvimento do modernismo.

\section{Grupo e obra: o modernismo gaúcho e a poesia de Augusto Meyer}

O contexto gaúcho é paradigmático para se entender a relação entre regionalismo e simbolismo como uma intersecção produtiva no desenvolvimento do modernismo brasileiro, o que pode ser visto no primeiro documento do grupo: os cinco volumes da revista Madrugada (1926). Dois eventos do ano anterior preparam o ambiente para Madrugada: Moysés Vellinho (escrevendo com o pseudônimo Paulo Arinos) trava uma polêmica nas páginas do Correio do Povo (16 de agosto de 1925) com Rubens Barcelos a propósito do "verdadeiro" regionalismo gaúcho, isto é, um regionalismo com um sentido de contemporaneidade, em que a validade da herança cultural e moral da figura do "gaúcho" paute a relação entre localismo e modernização. ${ }^{8}$ No mês seguinte ao início da polêmica, Guilherme de Almeida pronuncia sua já citada conferência

\footnotetext{
7 "Sua contribuição fundamental [do modernismo], que imprimiu ao espírito brasileiro uma direção decisiva, foi a conversão de valores até então havidos por negativos porque eram diferentes dos valores cosmopolitas - em positivos, por uma aceitação que parecia impraticável” (MORAES, NETO, 1941 apud KOIFMAN, 1985, p. 317). 8 A polêmica foi reproduzida em Barcellos (1955, p. 105-141).
} 
em Porto Alegre, que repercute nos círculos intelectuais dessa capital, gerando, em especial, uma resposta de Augusto Meyer, "Individualismo e brasilidade" (LEITE, 1972, p. 80), ${ }^{9}$ que buscava uma síntese entre local e universal no contexto do debate gaúcho.

Madrugada nos fornece um diagrama do campo de forças do grupo sul-rio-grandense (GOLIN, 2006). Destaca-se nela a presença de Augusto Meyer, que assina em todas as edições (exceto a n. 2) um tipo de texto programático em página encabeçada pelo logotipo da revista, ${ }^{10}$ além de publicar poemas, dois deles sob o pseudônimo Tristão Dadá. Junto desses textos e poemas de Meyer e de modernistas como Theodemiro Tostes, Ruy Cirne Lima e Athos Damasceno Ferreira, a revista traz o regionalismo mais ufanista da poesia de Vargas Netto e a prosa de Simões Lopes Neto e Darcy Azambuja, bem como uma seção chamada "Página da querência". O simbolismo na revista ocupa quase o mesmo espaço do modernismo, com poemas de Cruz e Sousa, Alceu Wamosy e Alphonsus de Guimaraens. Eduardo Guimarães e Mansueto Bernardi são os simbolistas cuja presença é mais constante no grupo, sendo que Mansueto editava livros de modernistas gaúchos pela editora da Livraria do Globo. Por fim, o ecletismo estético de Madrugada é complementado por um grande espaço destinado à crônica social e esportiva, que buscava retratar os hábitos da elite local, o que acaba por caracterizar o grupo como uma vertente mais sincrética e menos combativa do modernismo.

Tal sincretismo, entretanto, atingirá uma solução poderosa na poesia de Augusto Meyer, que pontua com sua produção poética os principais momentos do modernismo gaúcho: Coração verde (1926), Giraluz (1928), Duas orações (1928), Poemas de Bilu (1929) e Literatura e poesia (1931). Em seu primeiro livro, o poeta entrelaça a introspecção de corte simbolista e a referência regional enfática com um equilíbrio compositivo que incorpora procedimentos poéticos de Guilherme de Almeida e Ronald de Carvalho (CARVALHAL, 1984, p. 77-80). Essa junção conflui para um tipo de panteísmo, em que há uma fusão cósmica

\footnotetext{
${ }^{9} \mathrm{O}$ texto de Meyer é publicado no Correio do Povo em 17 de setembro de 1925, junto com o resumo da conferência de Guilherme. Some-se a esses fatos a presença em Porto Alegre do itinerante Raul Bopp, que divulgava os modernistas entre as diferentes cidades pelas quais passava.

${ }^{10}$ Há no fac-símile da revista n. 5 anotação à caneta atribuindo essas páginas a Meyer (Ver MADRUGADA, 2006).
} 
e solar do sujeito lírico com a natureza. Contudo, os matizes dessa fusão apontam não apenas para as tensões, mas também para as soluções futuras de Augusto Meyer. Por um lado, opera-se uma fusão solene e plácida, uma "alvorada religiosa" como a do poema "Alvorada", e que também pode ser lida em "Sombra verde" e "Grito". Por outro lado, esse aspecto religioso, que certamente é dominante no livro, convive com uma fusão mais febril e frenética, em que a solução integradora se faz pela dança, com sua "vertigem boa e louca", presente em poemas como "Ciranda" e "Cantiga de roda" (LEITE, 1975).

A dança, sobretudo o delírio de uma dança giratória, fissura a placidez de Coração verde e abre o caminho para a subjetividade cindida e inquieta de Giraluz, a qual evidencia, desde o título, a tensão entre a dissolução no elemento incorpóreo da luz, dando continuidade ao panteísmo solar do livro anterior, e o movimento do giro, a sua agitação. Some-se a isso o neologismo do título, certamente derivado de "girassol", o que também aponta para a maior abertura do livro de 1928 ao experimentalismo no âmbito da elaboração verbal. A hipótese que aqui proponho é a de que as diferentes conotações da dança em seus poemas pautam os diálogos literários de sua obra e abrem um prisma diferente de interpretação do modernismo brasileiro. Assim, em Giraluz, a dança é multifacetada e engloba a "dança branca da chuva" ("Seca") e "a dança loura do sol" ("Vindima"), que recuperam a relação com a natureza do livro anterior, o registro do momento triste, em que "[...] grave e triste/ dança o minuto na pausa do pêndulo" ("Órbita") e, principalmente, a dança como uma forma de intensificação da participação do sujeito lírico na linguagem, nos seus sentimentos e no mundo, seja no frenesi "dança batuque dança" ("Batuque"), no amor que "[...] também dança/ ao corrupio da ilusão" ("Violão") ou, por fim, na "Vontade simples de semear alegria/ pelos cinco sentidos,/ pela dança das palavras musicais!" ("Veranico").

Ao comentar Giraluz, Mário de Andrade (1928) nota que o livro acrescenta à poesia de Augusto Meyer o elemento popular das formas, das maneiras de sentir e das dicções, convergindo, acrescento, com propostas da poesia do próprio Mário. Desse modo, a poesia de Meyer dos dois primeiros livros articula a relação entre simbolismo introspectivo e regionalismo enfático do sistema literário gaúcho ao sistema literário nacional do modernismo brasileiro, que, por sua vez, é reconfigurado pelo modo original com que as poéticas de Ronald de Carvalho, Guilherme de 
Almeida e Mário de Andrade são absorvidas e modificadas por Coração verde e Giraluz. Nesse sentido, o regionalismo gaúcho passa a integrar o nacionalismo literário modernista, bem como a sondagem interior simbolista se transfigura pelo psicologismo poético e sua relação com a flexibilidade e o experimentalismo do verso livre.

Se, a partir de $1928,{ }^{11}$ o grupo gaúcho é um fator dinâmico e original na difusão e no estabelecimento do modernismo pelo país, a partir de 1929, com Poemas de Bilu, Augusto Meyer modifica radicalmente sua poética e cria um modo original e imprevisto de conceber a poesia modernista. A linguagem poética se altera, e o poeta constrói o seu alter ego Bilu. Os poemas agora incorporam plenamente a ambientação urbana, dão ênfase à linguagem coloquial, ao jogo de palavras e se expressam por um ritmo quebrado, entrecortado, que fragmenta por vezes a palavra, recorre a onomatopeias e utiliza-se de infrações à norma ortográfica, morfológica e sintática da língua escrita padrão. Essa elaboração poética desabusada corresponde ao personagem/poeta Bilu, cujo ataque frontal e direto a todas as convenções, incluindo aí o burguês e a rotina, reveste-se de um sarcasmo disseminado, que recorre constantemente ao absurdo, aos estados de insanidade e embriaguez, bem como ao elemento lúdico e infantil. No todo, Bilu se apresenta como uma figura de negatividade, sob o signo do movimento constante, da abertura de infinitos caminhos de um Aleguá-Exu, como descreve no poema "Aleguá": "Ó camarada, quem fica apodrece,/ os caminhos foram feitos para andar./ Aleguá pelos caminhos que não param!".

Essa personalidade afim à de Macunaíma, que também se coloca sob o signo de Exu, ${ }^{12}$ passa a estabelecer um diálogo novo com a obra de Mário de Andrade, em que são destacados os seus aspectos de inconformismo, de inquietação subjetiva e de confrontação social. Assim, o desvairismo de Mário tem como contraponto o poema "Delirismo", em que "O anarquista cospe fogo./ Traga-balas come bomba", e cujo sarcástico frenesi pode ser lido como uma reconfiguração da lógica de "Danças", de Mário (publicado em Estética, n. 3, 1924). A lógica desse

${ }^{11}$ Em 1928, além de Giraluz, são publicados os livros Gado xucro, de Vargas Netto, Colônia Z, de Rui Cirne Lima, Novena à Nossa Senhora da Graça, de Theodemiro Tostes, Trem da serra, de Ernani Fornari, Rodeio de estrelas, de Manoelito Ornelas e Saco de viagem, de Tirteu Rocha Viana.

12 Ver o capítulo VII, "Macumba”, de Macunaíma (1928). 
poema, com seu cinismo programático (a "dança de ombros"), suas associações livres e sua velocidade giratória reaparecem acrescidas de ferocidade no poema "Chewing gum", de Meyer:

Masco e remasco a minha raiva, chewing gum.

Que pílula este mundo!

Roda sem parar.

Zero zero zero zero

É uma falta de imprevisto...

Quotidianissimamente enfastiado, engulo a pílula ridícula, janto universo e como mosca.

Comi o mio-mio das amarguras.

A raiva dói como um guasqueaço.

Angurreado.

Amolado

Paulificado

Bilu, pensa nas madrugadas que virão, aspira a força da terra possante e contente.

Cada pedra no caminho é trampolim.

$\mathrm{O}$ futuro se conjuga saltando.

Depois:

indicativo presente -

caio em mim.

O poema se compõe com os mesmos elementos com os quais o grupo modernista gaúcho se constituiu: a imersão subjetiva de matriz simbolista, com o poeta cismando na própria dor, e o regionalismo gaúcho, presente não apenas no léxico ("mio-mio", "guasqueaço", "angurreado") 13 mas igualmente no vitalismo das "madrugadas que virão", da "força da terra possante". Contudo, esses materiais entram no poema sob o signo da negatividade: o vitalismo é sarcasticamente desautorizado por um jogo metalinguístico entre futuro e presente verbais,

13 "Mio-mio" é um tipo de arbusto típico da América do Sul, uma planta tóxica para o gado; "guasca" é uma tira de couro cru; "angurreado" significa aborrecido, angustiado. 
e o subjetivismo se resume a uma queda no pronome "mim", índice da subjetividade que se configura como um limite intransponível, entre banal e fatal. A própria cisma se torna um ato de mascar a raiva como se masca um chiclete composto de fastio e amargura, o que se desdobra no poema como fúria, conferindo uma gestualidade intratável aos versos, que se expandem e se contraem em um ritmo nervoso e agressivo.

Além do jogo entre pronomes e personalidade subjetiva, presente na parte III do poema "Danças", de Mário de Andrade, e da sugestão rítmica da parte I, com seu verso longo inicial seguido dos versos ágeis e entrecortados, Meyer parece ter sido particularmente sensível a esses versos da parte VI: "Parceiro, tu sabes a dança do ventre/ Mas eu vou te ensinar dança melhor/ Olha: a Terra é uma bola/ A bola gira/ Gira o universo/ Os homens giram também// Tudo é girar, tudo é rodar" (ANDRADE apud PASINI, 2013, p. 95). ${ }^{14}$ Meyer absorve as ideias de que o ridículo cotidiano pode ser simbolizado pela banalidade de uma bola que gira e de que a repulsa sarcástica a esse universo envolve de modo autoirônico, senão autodestrutivo, o sujeito lírico e o ritmo do poema no mesmo ritmo giratório do mundo, em um tipo de frenesi de ódio e angústia. No entanto, a repulsa pelo mundo é maior em Meyer, seu ritmo é mais contundente, a bola do mundo é veiculada por uma imagística mais violenta: "zero zero zero zero" e "pílula ridícula", que se desdobra em mio-mio, mosca e na própria "goma de mascar" ("chewing gum"). É notável nesse sentido que, além de travar um diálogo que incorpora a poesia de Mário no contexto do modernismo gaúcho, Meyer também estabelece uma leitura diferente da poesia de Mário pela originalidade de seu próprio poema. Assim, os aspectos negativos, o inconformismo e a violência da forma poética estão mais presentes em "Chewing gum" do que em "Danças", o que nos permite abrir uma nova perspectiva sobre as potencialidades de interpretação do poema de Mário.

Entretanto, a que se deve a virada bilusiana de Augusto Meyer e o que ela pode dizer sobre a importância dos grupos no modernismo brasileiro? Embora a virada bilusiana de Meyer seja um tema em aberto, sobretudo em suas possíveis motivações e mediações extraliterárias, é possível descrevê-la como um modo de intensificação do elemento lúdico no modernismo gaúcho e como sua radicalização crítica. O caráter lúdico aparece nos poemas "O Globo" e "Puladinho", que Augusto Meyer

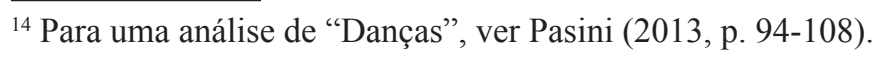


publicou nos números 3 e 4, respectivamente, da revista Madrugada, sob o pseudônimo Tristão Dadá. A que se deve esse pseudônimo? Certamente, tratava-se de uma blague com o dadaísmo, sentido então como simples brincadeira, o que reaparece de modo um pouco mais problematizado no poema "Dadá", de Giraluz. Todavia, a radicalização de Bilu se evidenciou como um modo de levar Dadá a sério. $\mathrm{O}$ próprio nome "Bilu", se entendido como um gesto de dirigir-se a bebês ("bilu-bilu"), parece corresponder a uma das acepções de "Dadá": uma onomatopeia do balbucio infantil. Além disso, o poema "Puladinho" é republicado sem alterações no livro de 1929, o que marca a transição do Tristão Dadá, lúdico e descompromissado que se perde na efemeridade de uma revista, ao Bilu, "malabarista metafísico,/grão tapeador parabólico" ("Canção encrencada"), que se confirma no ideal de perenidade do livro. Nesse sentido, a poética de Poemas de Bilu, com seus absurdos, agressões, estridências sonoras e imagéticas, pode ser entendida não como um livro dadaísta no modernismo brasileiro, mas como um livro modernista que incorpora sistematicamente as atitudes e estratégias estéticas de Dadá no contexto já consolidado do modernismo gaúcho e brasileiro.

Dessa perspectiva, é possível notar como Augusto Meyer alcança seu ponto de maior originalidade a partir de um trabalho coletivo não apenas do grupo gaúcho, mas também do diálogo entre grupos do modernismo brasileiro e da abertura para a vanguarda internacional. Assim, simbolismo e regionalismo gaúchos se conjugam com a abertura para o cotidiano, para o verso livre e o psicologismo da poesia de Mário de Andrade, sobretudo de "Danças", que, por sua vez, dialogava dentro do grupo paulista com a associação livre vertiginosa de Luís Aranha. No entanto, o crescente interesse pela estética dadaísta, somado à angústia intensificada diante da vida social, levou Meyer a assumir uma atitude negativa diante dos materiais com que trabalhava. O livro poderoso de 1929 gerou assim uma perspectiva própria, a um tempo individual e coletiva, que permite a releitura do modernismo brasileiro a partir de um ponto específico, que é capaz de reconhecer as linhas de força de negatividade que sulcam o movimento. Desse modo, ao triangular o grupo gaúcho com a obra de Mário e a estética de Dadá, Augusto Meyer demonstra como o prisma dos grupos fundido com a originalidade individual cria pontos a partir dos quais o movimento modernista pode ser (re)mapeado. 


\section{Referências}

ANDRADE, M. de. Aspectos da literatura brasileira. Belo Horizonte: Itatiaia, 2002.

ANDRADE, M. de. Livros. Diário Nacional. São Paulo, 14 out. 1928. Não paginado.

ANDRADE, M. de. Macunaíma: o herói sem nenhum caráter. São Paulo: [s.n.], 1928.

ANDRADE, M. de. Osvaldo de Andrade. Revista do Brasil, São Paulo, ano IX, v. XXVII, p. 26-32, set./dez. 1924.

ANDRADE, O. de. Um homem sem profissão. São Paulo: Globo, 2002.

BARCELLOS, R. Estudos rio-grandenses. Porto Alegre: Globo, 1955.

BATISTA, M. R.; LOPEZ, T. P. A.; LIMA, Y. S. de. Brasil: 1o tempo modernista - 1917/29. Documentação. São Paulo: IEB, 1972.

BOURDIEU, P. The field of cultural production. New York: Columbia University Press, 1994.

BRETON, A. L'amour fou. Oeuvres complètes II. Paris: Gallimard, 1992. BRITO, M. da S. Ângulo e horizonte. São Paulo: Livraria Martins, 1969. CANDIDO, A. Teresina etc. Rio de Janeiro: Ouro sobre Azul, 2007.

CARVALHAL, T. F. A evidência mascarada (um estudo da poesia de Augusto Meyer). Porto Alegre: L\&PM; Brasília: INL, Fundação Nacional Pró-Memória, 1984.

CAVAlCANTE, M. N. B. Clima. Contribuição para o estudo do modernismo. 1978. Dissertação (Mestrado em Literatura Brasileira) Faculdade de Filosofia, Letras e Ciências Humanas, Universidade de São Paulo, São Paulo, 1978.

CHURCHILL, S. W. The little magazine Others and the renovation of modern American poetry. Burlington, VT: Ashgate Publishing, 2006.

COHEN, M. A. To stand on the rock of the word "We". In: DURÃO, F. A.; WILLIAMS, D. (Ed.). Modernist group dynamics: the politics and poetics of friendship. Cambridge, MT: Cambridge Scholars Publishing, 2008. 
DANTAS, V. Entre “A negra" e a mata virgem. Novos Estudos, São Paulo, n. 45 , p. 100-116, jul. 1996.

DENTON, K. A.; HOCKX, M. (Ed.). Literary societies in Republican China. Lanham, MD: Lexington Books, 2008

DERRIDA, J. Mal de arquivo: uma impressão freudiana. Tradução de Cláudia de Moraes Rego. Rio de Janeiro: Relume Dumará, 2001.

FONSECA, M. A. Oswald de Andrade: biografia. São Paulo: Globo, 2008.

GOLIN, C. Em Porto Alegre, a Madrugada literária dos modernistas. In: RAMOS, P. (Org.). A madrugada da modernidade (1926). Porto Alegre: Uniritter Ed., 2006.

GUELFI, M. L. F. Novíssima: estética e ideologia na década de vinte. São Paulo: IEB-USP, 1987.

KOIFMAN, G, (Org.). Cartas de Mário de Andrade a Prudente de Moraes, neto (1924/36). Rio de Janeiro: Nova Fronteira, 1985.

LEITE, L. C. M. Cirandagem: introdução à poesia de Augusto Meyer. Revista de Letras, Faculdade de Filosofia, Ciências e Letras, Assis, n. 17, p. 9-38, 1975.

LEITE, L. C. M. Modernismo no Rio Grande do Sul. São Paulo: IEBUSP, 1972.

LEITE, R. M. Flávio de Carvalho: o artista total. São Paulo: Editora Senac, 2008.

MADRUGADA. Porto Alegre: Uniritter Ed., 2006. Edição fac-similar. Original publicado em 1926.

MEYER, A. Poesias: 1922-1955. Rio de Janeiro: Livraria São José Editora, 1957.

MICELI, S. Intelectuais e classe dirigente no Brasil (1922-1945). São Paulo: Difel, 1979.

MORAES, NETO, P. Literatura de ideias apud KOIFMAN, G. Cartas de Mário de Andrade a Prudente de Moraes, neto (1924/36). Rio de Janeiro: Nova Fronteira, 1985. 
MORESCHI, M. A façanha auto-historiográfica do modernismo brasileiro. 2010. Tese (Doutorado em Hispanic Languages and Literature) - University of California, Santa Barbara, 2010.

PASINI, L. A apreensão do desconcerto: subjetividade e nação na poesia de Mário de Andrade. São Paulo: Nankin, 2013.

PAULA, R. A. O expressionismo na biblioteca de Mário de Andrade: da leitura à criação. 2007. $171 \mathrm{f}$. Tese (Doutorado em Literatura Brasileira) - Faculdade de Filosofia, Letras e Ciências Humanas, Universidade de São Paulo, São Paulo, 2007.

RAMOS, P. E. da S. Introdução. . Poesia simbolista: antologia. São Paulo: Melhoramentos, [s.d.].

SANT'ANNA, M. M. de. História do modernismo em Alagoas (19221932). Maceió: EDUFAL, 1980.

XAVIER, L. R. Patrimônio em prosa e verso: a correspondência de Rodrigo Melo Franco de Andrade para Augusto Meyer. 2008. 156 f. Dissertação (Mestrado Profissionalizante em Bens Culturais e Projetos Sociais) - Centro de Pesquisa e Documentação de História Contemporânea do Brasil, Fundação Getulio Vargas, Rio de Janeiro, 2008. 